\title{
An Estimation of the Probability Distribution of Wadi Bana Flow in the Abyan Delta of Yemen
}

\author{
Khader B. Atroosh (Corresponding author) \\ AREA, Elkod Agricultural Research Station, Abyan, Yemen \\ P.O. Box 6035, Kormaksar, Aden \\ Tel: 967-773-229-056 E-mail: kbatroosh@hotmail.com
}

\author{
Ahmed T. Moustafa \\ International Center for Agricultural Research in the Dry Areas (ICARDA) \\ Dubai Office, P.O. Box 13979, Dubai, UAE \\ Tel: 971-50-636-7156 E-mail: a.moustafa@cgiar.org
}

Received: January 5, 2012 Accepted: January 29, 2011 Online Published: April 17, 2012

doi:10.5539/jas.v4n6p80 URL: http://dx.doi.org/10.5539/jas.v4n6p80

\begin{abstract}
Wadi Bana is one of the main Wadies in Yemen, where different quantities of water reach the Delta and depends on the amounts of rainfall in the wadi watershed. In order to estimate the spate water flow distribution probability, data on water flow were collected during the period from 1948 to 2008. Seven probability distributions, namely, Gamma, Weibull, Pearson 6, Rayleigh, Beta, Kumaraswamy and Exponential distributions were tested to model the distribution of the Wadi Bana flows and Kolmogorov-Smirnov, Anderson-Darling and Chi- Squared goodness-of-fit tests were used to evaluate the best fit at $5 \%$ level of significance. It suggests that the best frequency distribution obtained for the Wadi Bana flows in the Abyan Delta of Yemen is Gamma followed by weibull distribution for both summer and autumn seasons. The annual maximum runoff was 286.6 million $\mathrm{m}^{3}$ in the 1957 and the minimum runoff was 30.4 million $\mathrm{m}^{3}$ in 1974. The estimated flow during wet, medium and dry years were 103-134, 76-103 and 55-76 million $\mathrm{m}^{3}$ respectively for autumn season and 52-81, 29-52 and 15-29 million $\mathrm{m}^{3}$ respectively for summer season. The flow in autumn season reaches about $70 \%$ of total annual flows.
\end{abstract}

Keywords: Spate water flows, Probability distribution, Wadi Bana, Delta Abyan, Yemen

\section{Introduction}

The Abyan delta plain is located in an arid to sub-tropical area, approximately between latitudes $13^{\circ} 04^{\prime}$ to $13^{\circ} 18^{\prime}$ $\mathrm{N}$, and longitudes $45^{\circ} 08^{\prime}$ to $45^{\circ} 30^{\prime} \mathrm{E}$. It lies at the Gulf of Aden, about $55 \mathrm{~km}$ east of Aden. Wadi Bana is one of the main Wadies in Yemen, where different quantities of water reach the Delta and depending on the amount of rainfall in the wadi watershed. Catchment area of wadi Bana upstream is about 7,200 sq km.

The flow of Wadi Bana is distinguished by flood fluctuation (flash floods). Under normal condition, the average annual flow is 162 million $\mathrm{m}^{3}$, or $6 \%$ of the total of catchment rainfall, the annual frequency of flood is fairly high and reaches 19 floods per year (Atkins W.S. And Partner, 1984). Average annual peak flood is $980 \mathrm{~m}^{3} \mathrm{~s}-1$, and baseflow is estimated 400 million $\mathrm{m}^{3}$ (Negenman, 1995). $90 \%$ of the flood is utilized for irrigation, of which $66 \%$ is applied during autumn irrigation season (1 July to 15 October) and the remaining during the summer season (16 March to 31May). The fluctuation in flood flow is a major hydraulic criteria for assessment of flood risk, water resources management and hydraulic structure design such as dams, reservoirs, irrigation canals, weirs and irrigation ditches, and prevention of damages due to flood require an adequate knowledge of extreme events of high return periods (Tao, et al, 2002). It is necessary to determine the recurrence or timing for flood flow, and quantitative flow of flood and intervals, which can be achieved by flood frequency analysis methods and involves the measurement of distribution pattern and extrapolation of cumulative distribution functions to calculate the extreme flood values.

The selection of appropriate model depends mainly on the characteristics of available flood flow data at the 
particular site. Hence, it is necessary to evaluate many available distributions in order to find a suitable model that could provide accurate extreme flood flow estimates.

Spate hydrology is distinguished by a vast change in flood frequency and quantitative aspect which directly has an impact on availability of water for irrigation.

This issue have been emphasized by, Abdul Krim M.D., and Chowdhury J. U. (1995) who studied several distributions for flood flows in Bangladesh, Abida and Ellouze (2008) applied several distributions for flood flows in Tunisia, and Ghorbani et al (2010) who compared several distributions for flood frequency analysis in Iran. This study aimed to determine the best fit probability distribution for the prediction of flows in Wadi Bana in Abyan Delta of Yemen.

\section{Literature Review}

Reference to Benson (1968), and Vogel et al. (1993) used several distributions for describing flood flows in the USA. The Natural Environment Research Council undertook a flood study for UK conditions (NERC, 1975). McMahon and Srikanthan (1981) evaluated flood distributions for Australian conditions. Rossi et al. (1984) and Ahmed et al. (1988) studied flood distributions for Italy and Scotland, respectively. The flood distributions for Turkey were investigated by Haktanır (1991, 1992) and Haktanır and Horlacher (1993), while Mutua (1994) compared several frequency distributions for floods in Kenya.

Vogel and Wilson (1996) summarize investigations around the world and show that a consensus is emerging that the distribution of annual maximum floods is perhaps best approximated by a generalized extreme value (GEV) PDF. They also document that the GEV PDF provides a good fit to annual flood series at 1,490 sites across the continental United States.

Abida H. and Ellouze M. (2008) applied L (Linear) moments to calculate regional flood frequency distributions for different zones in entire Tunisia, trough data collection from 42 stations for a period of 27 years. five frequency distributions are used for analysis of hydrologic extreme variables, they are: (i) Generalized Extreme Value (GEV), (ii) Pearson Type III (P3), (iii) Generalized Logistic (GLO), (iv) Generalized Normal (GN), and (v) Generalized Pareto (GPA). Spatial trends, with respect to the best-fit flood frequency distribution, are distinguished: Northern Tunisia was shown to be represented by the GNO distribution while the GNO and GEV distributions give the best fit in central/southern Tunisia.

Topaloglu F. (2002), applied the Gumbel, log-Logistic, Pearson-3, log-Pearson-3 and log-Normal-3 distributions to the series of annual instantaneous flood peaks and annual peak daily precipitation for 13 flow gauging and 55 precipitation gauging stations in the Seyhan basin, respectively. The parameters of the distributions were estimated by the methods of moments (MOM) and probability weighted moments (PWM). A detailed chi-squared and Kolmogorov-Smirnov (K-S) goodness-of-fit tests were also applied. According to the evaluations of chi-squared tests, Gumbel (MOM) for both flow and precipitation stations in the Seyhan river basin were found to be the best models. As a result of the K-S test, log-Normal-3 (MOM) and log-Pearson-3 (MOM) models were determined to be the best for flow and precipitation stations, respectively.

Olukanni D.O. and Salami A.W. (2008), evaluated several probability distribution analysis methods for the prediction of reservoir inflow at hydropower dams in Nigeria which includes Kainji, Shiroro and Jebba. The reservoir inflow data were subjected to probability distribution analysis including Gumbel, normal, log-Pearson type III, and log-normal. The selection of the appropriate probability distribution model for each hydropower dam was based on goodness of fit tests. The values of goodness of fit for each of the hydropower dams are $\mathrm{r}=$ $0.95, R^{2}=0.96$ for Kanji, $r=1.00, R^{2}=0.99$ for Shiroro, and $r=0.88, R^{2}=0.96$ for Jebba. For the Kanji and Shiroro hydropower dams the log-Pearson type III model gave the best fit, while for Jebba the best fit model was log-normal.

Aksoy, H. (2000, 2007), Karmakar, S. and Simonovic, S.P. (2009), Hughes, B. L. and Saunders, A. M. (2002) reported that gamma distribution is the best analysis tool for prediction of flood frequency.

\section{Material and Methods}

The Wadi Bana flow data for the period of 61 years from 1948 to 2008 were obtained from the Irrigation Department in the Delta Abyan, Agricultural Affice, Abyan Governorate. The nature of data involves flood flow volumes (million cubic meter) recorded for autumn and summer seasons of the year. Probability distribution analysis of Wadi Bana flow was detected in accordance with the following equations (Georgiev G. V. et al. (1991):

$$
M_{m}=\frac{\sum M_{i}}{n}
$$




$$
\begin{aligned}
& C_{v}=\sqrt{\frac{\sum\left(K_{i}-1\right)^{2}}{n-1}} \\
& K_{i}=\frac{M_{i}}{M_{m}} \\
& C_{s}=\frac{\sum\left(K_{i}-1\right)^{3}}{(n-1) C_{v}{ }^{3}} \\
& P_{i}=\frac{i}{n+1} 100 \\
& K_{p} \%=\frac{M_{p} \%}{M_{m}}=\varnothing C_{v}+1 \\
& M_{p} \%=K_{p} \% * M_{m}=M_{m}\left(\varnothing C_{v}+1\right)
\end{aligned}
$$

Where:

$\mathrm{M}_{\mathrm{m}}$ - mean flow, $\sum \mathrm{M}_{\mathrm{i}}$ - total flow, n-number of years, $\mathrm{C}_{\mathrm{v}}$ - Coefficient of variation, $\mathrm{K}_{\mathrm{i}}$ - percent of the respective observed flow into the mean flow, $\mathrm{C}_{\mathrm{s}}$ - coefficient of asymmetry, $\mathrm{P}_{\mathrm{i}}$ - probability distribution, $\mathrm{K}_{\mathrm{p}} \%$ - correction factor, $\theta$ - Foster factor from Foster-Ribkin table, $\mathrm{M}_{\mathrm{p}} \%$ - Estimated flow corresponding to the ranked probability. Values of $\theta$ were calculated by using the Foster and Ribkin table at the deferent values of coefficient of asymmetry corresponding to the deferent probability.

For determination of the fitting probability distribution of Wadi Bana flows, the software EasyFit professional version 5.4 (http://www.mathwave.com) is used . EasyFit is a data analysis program and simulation application that enables fitting probability distributions to sample data, select the best model, and apply the analysis results to make better decisions.

Seven different probability distributions are considered, some of which are very widely used in hydrologic frequency analysis. These distributions include: Gamma, Weibull, Pearson 6, Rayleigh, Beta, Kumaraswamy and Exponential distributions. These distributions and their probability density functions are presented in Table 1 . Three goodness-of-fit tests were conducted, Kolmogorov-Smirnov, Anderson-Darling and Chi-Squared evaluate the best fit at $5 \%$ level of significance. In this study, the software CumFreq (www.waterlog.info) is used for determination of return periods of maximum flow.

\section{Results and Discussion}

During the 61 year period between 1948 and 2008, the maximum annual runoff was recorded at 286.6 million $\mathrm{m}^{3}$ in 1957 while the minimum runoff was registered at 30.4 million $\mathrm{m}^{3}$ in 1974 (table 3). Over the same period the average runoff value calculated at 83.152 Million cubic meters for autumn and 38.415 for summer. Meanwhile, the general statistical analysis of the flows data indicates that the skewness for autumn is 1.2827 and for summer is 1.8176 . The coefficient of variation recorded at 0.4601 and 0.8316 for autumn and summer respectively (Table $3)$.

The obtained results of probability flow were calculated accordingly to the year classification, very wet, wet, medium, dry and very dry Saloua, R et al, (2012), Adejuwon J.O et al, (2007).

The estimated flow during wet, medium and dry years were $103-134,76-103$ and $55-76$ million $\mathrm{m}^{3}$ respectively for autumn season and $52-81,29-52$ and $15-29$ million $\mathrm{m}^{3}$ respectively for summer season (Table 4). The flow in autumn season occupies about $70 \%$ of total annual flows.

The applied statistical results in this study is in agreement with the results obtained by application of Gamma Distribution, with average run-off recorded during study period. The average actual recorded data for autumn and summer are 83.15 and 38.42 million $\mathrm{m}^{3}$ /year respectively (Table 3) and is identical with the value calculated by Gamma Distribution by using the software EasyFit professional version 5.4 (table 4), and similarly agree with statistical parameters coefficient of variation, Standard deviation (Tables 3 and 5).

Comparison of maximum and minimum actual run-off recorded and applied in this study with those obtained from EasyFit program, we observed the quantities are close with the data found from Gamma Distribution, where the maximum ran-off quantity frequent every 33 years with probability of $3 \%$, where as the minimum run-off will occur every 33 years with probability $97 \%$ (Table 7). 
Figures 1 and 2 show the theoretical curve of the probability flow and distribution of the observed flow during autumn and summer respectively, the correlation coefficient between them has been 0.98 and 0.98 respectively. Figures 3 and 4 show the cumulative distribution during the autumn and summer respectively, where it is noted a direct proportion between observations $(\mathrm{x})$ and the cumulative distribution $\mathrm{f}(\mathrm{x})$.

Summary of statistical analysis for Wadi Bana flows during the period of $(1948$ - 2008) under the studied distributions are shown in table 5. The obtained fitting results-parameters of distribution equations used in this study have been shown in table 2 .

Kolmogorov-Smirnov, Anderson-Darling and Chi-Squared goodness-of-fit tests indicate that all the models can be used to describe the distribution of spate flows of Wadi Bana in the Abyan Delta of Yemen. From the results of seven frequency distributions applied in this study, it suggests that the best frequency distribution obtained for the Wadi Bana spate flows in the Abyan Delta of Yemen is Gamma followed by weibull distributions for the both seasons autumn and summer (Table 6). These results are supported with previous studies Aksoy, H. (2000, 2007), Karmakar, S. and Simonovic, S.P. (2009), Hughes, B. L. and Saunders, A. M. (2002).

Tables 7 and 8 Show the quantile estimates for return periods up to 100 and 500 years by using Easyfit and CumFreq software programs respectively for cumulative frequency analysis.

Table 8 shows the quantitative and frequency of flood run-off in Wadi Bana during the seasons autumn and summer by utilizing CumFreq Program and selection of the best fitting of all distributions, where the frequency of flood run-off every 100 years is estimated approximately 266 and 113 million $\mathrm{m}^{3} /$ year during autumn and summer respectively, compared to the quantity of run-off for the same period by utilizing EasyFit Program, it is observed that Pearson 6 Distribution is closer and recorded 262 million $\mathrm{m}^{3} /$ year during autumn season only, but does not fit for the seasonal run-off during summer season (Table 7), in comparison with other distributions, it is observed that the quantity of run-off frequency for every 100 years (Table 7) fluctuates than those shown in table 8. This is explained that prediction of run-off can be relied by application of studied distributions for 100 year frequency period or less, and also depend on the prediction of run-off when the frequency period exceeds 100 years and probably reaches 500 years or more by application of CumFreq Program and selection of the best fitting of all distributions.

The obtained results may be useful for engineering planning, designs and irrigation planning in future and maximum season flows of Wadi Bana events can be predicted.

\section{Conclusions}

Basic statistical characteristics of Wadi Bana flows in the Abyan Delta of Yemen have been obtained using annual data recorded for 61 years. Seven probability distributions, namely, Gamma, Weibull, Pearson 6, Rayleigh, Beta, Kumaraswamy and Exponential distributions were tested to model the distribution of the Wadi Bana flows and Kolmogorov-Smirnov, Anderson-Darling and Chi-Squared goodness-of-fit tests were used to evaluate the best fit at $5 \%$ of level significant. It suggests that the best frequency distribution obtained for the Wadi Bana flows in the Abyan Delta of Yemen is Gamma followed by weibull distribution for both summer and autumn seasons.

\section{References}

Abdul Krim, M. D., \& Chowdhury, J. U. (1995). A comparison of four distributions used in flood frequency analysis in Bangladesh, Hydrological Sciences Journal, 40(1), 55-66. http://dx.doi.org/10.1080/02626669509491390

Abida, H., \& Ellouze, M. (2008). Probability distribution of flood flows in Tunisia. Hydrol. Earth Syst. Sci., 12, 703-714. http://dx.doi.org/10.5194/hess-12-703-2008

Adejuwon, J. O., Odekunle, T. O., \& Omotayo, M. O. (2007). Extended-Range Weather Forecasting in Sub-Saharan West Africa: Assessing a Potential Tool for Adapting Food Production to Climate Variability and Climate Change. AIACC Working Paper No. 46. [Online] Available: http://www.aiaccproject.org/working_papers/Working\%20Papers/AIACC_WP46_Adejuwon.pdf

Ahmed, M. I., Sinclair, C. D., \& Werritty, A. (1988). Log-Logistic Flood Frequency Analysis. Journal of Hydrology, 98, 3-4, 205-224. http://dx.doi.org/10.1016/0022-1694(88)90015-7

Akosy, H. (2000). Use of gamma distribution in hydrological analysis. Turkish Journal of Engineering and Environmental Sciences, 24, 419-428. AOnline] Available: http://mistug.tubitak.gov.tr/bdyim/abs.php?dergi=muh\&rak=9909-13 
Akosy, H. (2007). Hydrological variability of the European part of Turkey. Iranian Journal of Science \& Technology, Transaction B, Engineering, 31(B2), 225-236. [Online] Available: http://www.shirazu.ac.ir/en/files/extract_file.php?file_id $=720$

Atkins, W. S., \& Partner. (1984). Feasipility study for Wadi Bana and Abyan Delta Development Project, Main Report, Vol. I, MAAR, PDRY.

Benson, M. A. (1968). Uniform Flood Frequency Estimating Methods for Federal Agencies. Water Resources Research, 4(5), 891-908. http://dx.doi.org/10.1029/WR004i005p00891

Georgiev, G., Darjanov, K., Dulov, S., Uzunov, N., \& Ovacharova, A. (1991). Exercise Book of Agricultural Melioration for Students of Higher Agricultural Institute-Plovdiv. Zemia, ISPN 954-05-0032-X, Sofia, 1991 (In Bulgarian).

Ghorbani, M. A., Ruskeep, H., Singh, V. P., \& Sivakumar, B. (2010). Flood frequency analysis using Mathematica. Turkish Journal of Engineering and Environmental Sciences, 34, 171-188. http://dx.doi.org/10.3906/muh-1002-2

Haktanir, T. (1991). Statistical Modeling of Maximum Flows in Turkish Rivers. Hydrol. Sci. J., 36(4), 367-389. [Online] Available: http://iahs.info/hsj/hsj364.htm

Haktanir, T. (1992). Comparison of Various Flood Frequency Distributions Using Annual Flood Peaks Data of Rivers in Anatolia. Journal of Hydrology, 136, 1-31. http://dx.doi.org/10.1016/0022-1694(92)90002-D

Haktanir, T., \& Horlacher, H. B. (1993). Evaluation of Various Distributions for Flood Frequency Analysis. Hydrological Sciences Journal., 38, 15-32. [Online] Available: http://iahs.info/hsj/hsj381.htm

Lloyd-Hughes, B., \& Saunders, M. A. (2002). A drought climatology for Europe. International Journal of Climatology, 22, 1571-1592. http://dx.doi.org/10.1002/joc.846

Karmakar, S., \& Simonovic, S.P. (2009). Bivariate flood frequency analysis. Part 2: a copula-based approach with mixed marginal distributions. Journal of Flood Risk Management, 2(1), 32-44. http://dx.doi.org/10.1111/j.1753-318X.2009.01020.x

McMahon, T. A, \& Srikanthan, R. (1981). Log-Pearson Type 3 Distribution-Is It Applicable to Flood Frequency Analysis of Australian Streams. Journal of Hydrology, 52, 1-2, 139-147. http://dx.doi.org/10.1016/0022-1694(81)90100-1

Mutua, F. M. (1994). The Use of the Akaike Information Criterion in the Identification of an Optimum Flood Frequency Model. Hydrol. Sci. J., 39, 235-244.

Neggenman, A. J. H. (1995). Water Resources, Abyan Delta, Report WRAY-34, March 1995.

NERC. (1975). Flood Studies Reports. Natural Environment Research Council. London, Vols. 1-5.

Olukanni, D. O., \& Salami A. W. (2008). Fitting Probability Distribution functions to Reservoir Inflow at Hydropower dams in Nigeria. Journal of Environmental Hydrology, 16, 35. [Online] Available: http://www.hydroweb.com

Rossi, F., Fiorentino, M., \& Versaece, P. (1984). Two-Component Extreme Value Distribution for Flood Frequency Analysis. Water Resources Research, 20(7), 847-856. http://dx.doi.org/10.1029/WR020i007p00847

Saloua, R., Barbara, R., Mohammed, B., Abdelaziz, M., \& Mohammed, Y. K. M. (2012). Climate change impacts on water supply and demand in Rheraya Watershed (Morocco), with potential adaptation strategies. Water 2012, 4, 28-44. http://dx.doi.org/10.3390/w4010028

Tao, D. Q, Nguyen, V. T., \& Bourque, A. (2002). On selection of probability distributions for representing extreme precipitations in Southern Quebec. Annual Conference of the Canadian Society for Civil Engineering. 5th -8th June 2002, Canada, pp 1-8.

Topaloglu, F. (2002). Determining Suitable Probability Distribution Models for Flow and Precipitation Series of the Seyhan River Basin. Turkish Journal of Agriculture and Forestry, 26, 187-194. [Online] Available: http://mistug.tubitak.gov.tr/bdyim/toc.php?dergi=tar\&yilsayi=2002/4

Vogel, R. M., \& Wilson, I. (1996). Probability Distribution of Annual Maximum, Minimum and Average Streamflow in the United States. Journal of Hydrological Engineering, ASCE 1, 69-76. http://dx.doi.org/10.1061/(ASCE)1084-0699(1996)1:2(69) (8 pages) 
Vogel, R. M., Thomas, W. O., \& McMahon, T. A. (1993). Flood Flow Frequency Model Selection in the Southwestern United States. Journal of Water Resources Plan. Manage, ASCE, 119, 353-366. http://dx.doi.org/10.1061/(ASCE)0733-9496(1993)119:3(353) (14 pages)

Table 1. Probability distributions and their density functions

\begin{tabular}{lcc}
\hline \multicolumn{1}{c}{ Distribution } & $\mathrm{PDF}$ & $\mathrm{CDF}$ \\
\hline Gamma & $f(x)=\frac{x^{\alpha-1}}{\beta^{\alpha} \Gamma(\alpha)} \exp (-x / \beta)$ & $\mathrm{F}(x)=\frac{\Gamma_{x / \beta}(\mathrm{x})}{\Gamma(\mathrm{x})}$ \\
Weibull & $f(x)=\frac{\alpha}{\beta}\left(\frac{x}{\beta}\right)^{\alpha-1} \exp \left(-\left(\frac{x}{\beta}\right)^{\alpha}\right)$ & $F(x)=1-\exp \left(-\left(\frac{x}{\beta}\right)^{\alpha}\right)$ \\
Pearson 6 & $f(x)=\frac{(x / \beta)^{\alpha_{1}-1}}{\beta B\left(\alpha_{1}, \alpha_{2}\right)(1+x / \beta)^{\alpha_{1}+\alpha_{2}}}$ & $F(x)=I_{x /(x+\beta)}\left(\alpha_{1}, \alpha_{2}\right)$ \\
Rayleigh & $f(x)=\frac{x}{\sigma^{2}} \exp \left(-\frac{1}{2}\left(\frac{x}{\sigma}\right)^{2}\right)$ & $F(x)=1-\exp \left(-\frac{1}{2}\left(\frac{x}{\sigma}\right)^{2}\right)$ \\
Beta & $f(x)=\frac{1}{B\left(\alpha_{1}, \alpha_{2}\right)} \frac{(x-a)^{\alpha_{1}-1}(b-x)^{\alpha_{2}-1}}{(b-a)^{\alpha_{1}+\alpha_{2}-1}}$ & $F(x)=I_{z}\left(\alpha_{1}, \alpha_{2}\right)$ \\
Kumaraswamy & $f(x)=\frac{\alpha_{1} \alpha_{2} z^{\alpha_{1}-1}\left(1-z^{\alpha_{1}}\right)^{\alpha_{2}-1}}{(b-a)}$ & $F(x)=1-\left(1-z^{\alpha_{1}}\right)^{\alpha_{2}}$ \\
Exponential & $f(x)=\lambda \exp (-\lambda x)$ & $F(x)=1-\exp (-\lambda x)$ \\
\hline
\end{tabular}

Table 2. Fitting Results-Parameters

\begin{tabular}{|c|c|c|}
\hline Distribution & Autumn & Summer \\
\hline Gamma & $\alpha=4.7238 \beta=17.603$ & $\alpha=1.446 \beta=26.566$ \\
\hline Weibull & $\alpha=2.6145 \quad \beta=91.259$ & $\alpha=1.3755 \beta=44.954$ \\
\hline Pearson 6 & $\alpha_{1}=2.8057 \quad \alpha_{2}=1.9423 \mathrm{E}+8 \quad \beta=6.2924 \mathrm{E}+9$ & $\alpha_{1}=1.6929 \quad \alpha_{2}=1.6469 \mathrm{E}+7 \quad \beta=4.0009 \mathrm{E}+8$ \\
\hline Rayleigh & $\sigma=66.346$ & $\sigma=30.651$ \\
\hline Beta & $\begin{array}{l}\alpha_{1}=1.7683 \quad \alpha_{2}=3.864 \\
a=13.2 \quad b=228.8\end{array}$ & $\begin{array}{l}\alpha_{1}=0.20711 \quad \alpha_{2}=1.2975 \\
a=1.8039 E-15 \quad b=217.71\end{array}$ \\
\hline Kumaraswamy & $\begin{array}{ll}\alpha_{1}=1.0 & \alpha_{2}=1.2 \\
a=16.5 & b=228.8\end{array}$ & $\begin{array}{l}\alpha_{1}=0.24352 \quad \alpha_{2}=1.2103 \\
a=2.4163 E-15 \quad b=182.48\end{array}$ \\
\hline Exponential & $\lambda=0.01203$ & $\lambda=0.02603$ \\
\hline
\end{tabular}


Table 3. Observed Wadi Bana Flows During the period of 1948-2008

\begin{tabular}{|c|c|c|c|c|c|c|c|c|c|c|c|}
\hline Year & Aut. & Sum. & Total & Year & Aut. & Sum. & Total & Year & Aut. & Sum. & Total \\
\hline 1948 & 64 & 3.7 & 67.7 & 1969 & 94.2 & 42.2 & 136.4 & 1990 & 127.3 & 0 & 127.3 \\
\hline 1949 & 58.1 & 29.5 & 87.6 & 1970 & 81 & 56.6 & 137.6 & 1991 & 29.5 & 42.9 & 72.4 \\
\hline 1950 & 167.7 & 41.4 & 209.1 & 1971 & 44.4 & 38.1 & 82.5 & 1992 & 50.6 & 37.8 & 88.4 \\
\hline 1951 & 149.1 & 39 & 188.1 & 1972 & 74 & 74.4 & 148.4 & 1993 & 63.3 & 23.1 & 86.4 \\
\hline 1952 & 102.8 & 18.6 & 121.4 & 1973 & 94.4 & 1.2 & 95.6 & 1994 & 53.2 & 3.6 & 56.8 \\
\hline 1953 & 128 & 50.9 & 178.9 & 1974 & 16.5 & 13.9 & 30.4 & 1995 & 61.3 & 2.2 & 63.5 \\
\hline 1954 & 228.8 & 50.1 & 278.9 & 1975 & 55.6 & 0 & 55.6 & 1996 & 120 & 50 & 170 \\
\hline 1955 & 125.4 & 40.8 & 166.2 & 1976 & 25.1 & 54.7 & 79.8 & 1997 & 130 & 60 & 190 \\
\hline 1956 & 107.1 & 20.8 & 127.9 & 1977 & 64.9 & 24.7 & 89.6 & 1998 & 90 & 40 & 130 \\
\hline 1957 & 117.9 & 168.7 & 286.6 & 1978 & 57.7 & 30 & 87.7 & 1999 & 60 & 20 & 80 \\
\hline 1958 & 59.5 & 25.5 & 85 & 1979 & 72.2 & 52.3 & 124.5 & 2000 & 65 & 30 & 95 \\
\hline 1959 & 111.8 & 19 & 130.8 & 1980 & 78.4 & 75.6 & 154 & 2001 & 60 & 30 & 90 \\
\hline 1960 & 55.5 & 72 & 127.5 & 1981 & 94.4 & 0 & 94.4 & 2002 & 60 & 20 & 80 \\
\hline 1961 & 76.9 & 13.8 & 90.7 & 1982 & 42.2 & 112.4 & 154.6 & 2003 & 70 & 30 & 100 \\
\hline 1962 & 136.2 & 15.1 & 151.3 & 1983 & 91.6 & 39.3 & 130.9 & 2004 & 66 & 29.5 & 95.5 \\
\hline 1963 & 127 & 137.8 & 264.8 & 1984 & 63.6 & 29.4 & 93 & 2005 & 84 & 58.2 & 142.2 \\
\hline 1964 & 163.5 & 52 & 215.5 & 1985 & 56.7 & 18.2 & 74.9 & 2006 & 61.5 & 25.3 & 86.8 \\
\hline 1965 & 68 & 38.9 & 106.9 & 1986 & 53.9 & 0 & 53.9 & 2007 & 61.5 & 25.3 & 86.8 \\
\hline 1966 & 79.3 & 17.7 & 97 & 1987 & 68.1 & 95.9 & 164 & 2008 & 58.2 & 32.1 & 90.3 \\
\hline 1967 & 75.9 & 72.7 & 148.6 & 1988 & 96.1 & 2.6 & 98.7 & - & - & - & - \\
\hline 1968 & 128.5 & 50.4 & 178.9 & 1989 & 44.9 & 43.4 & 88.3 & - & - & - & - \\
\hline \multicolumn{12}{|c|}{ Descriptive Statistics } \\
\hline \multicolumn{8}{|c|}{ Statistic } & \multicolumn{2}{|c|}{ Autumn } & \multicolumn{2}{|c|}{ Summer } \\
\hline \multicolumn{8}{|c|}{ Sample Size } & \multicolumn{2}{|c|}{61} & \multicolumn{2}{|c|}{61} \\
\hline \multicolumn{8}{|c|}{ Range } & \multicolumn{2}{|c|}{212.3} & \multicolumn{2}{|c|}{168.7} \\
\hline \multicolumn{8}{|c|}{ Mean } & \multicolumn{2}{|c|}{83.152} & \multicolumn{2}{|c|}{38.415} \\
\hline \multicolumn{8}{|c|}{ Variance } & \multicolumn{2}{|c|}{1463.7} & \multicolumn{2}{|c|}{1020.5} \\
\hline \multicolumn{8}{|c|}{ Std. Deviation } & \multicolumn{2}{|c|}{38.259} & \multicolumn{2}{|c|}{31.946} \\
\hline \multicolumn{8}{|c|}{ Coef. of Variation } & \multicolumn{2}{|c|}{0.4601} & \multicolumn{2}{|c|}{0.8316} \\
\hline \multicolumn{8}{|c|}{ Std. Error } & \multicolumn{2}{|c|}{4.8985} & \multicolumn{2}{|c|}{4.0903} \\
\hline \multicolumn{8}{|c|}{ Skewness } & \multicolumn{2}{|c|}{1.2827} & & 76 \\
\hline & & & Excess & urtosis & & & & & 561 & & 195 \\
\hline
\end{tabular}

Table 4. Probability Distribution of Wadi Bana Flow Million Cubic meter

\begin{tabular}{ccccccccc}
\hline \multirow{2}{*}{ Season } & \multicolumn{8}{c}{ Probability, $\mathrm{P} \%$} \\
\cline { 2 - 7 } & 5 & 10 & 25 & 50 & 75 & 90 & & $\mathrm{C}_{\mathrm{v}}$ \\
\hline Autumn & 156 & 134 & 103 & 76 & 55 & 44 & 0.460 & 1.2 \\
Summer & 102 & 81 & 52 & 29 & 15 & 8 & 0.832 & 1.8 \\
Total & 258 & 215 & 155 & 105 & 70 & 52 & & \\
\hline
\end{tabular}


Table 5. Summary of statistics for Wadi Bana Flows (1948 - 2008)

\begin{tabular}{lccccc}
\hline \multicolumn{1}{c}{ Distributions } & Mean & $\begin{array}{c}\text { Standard } \\
\text { Division }\end{array}$ & C.V. & Skewness & Kurtosis \\
\hline Gamma & \multicolumn{5}{c}{ Autumn } \\
Weibull & 83.15 & 38.26 & 0.460 & 0.920 & 1.270 \\
Pearson 6 & 81.07 & 33.33 & 0.411 & 0.309 & -0.186 \\
Rayleigh & 90.90 & 54.27 & 0.597 & 1.194 & 2.138 \\
Beta & 83.15 & 43.47 & 0.523 & 0.631 & 0.245 \\
Kumaraswamy & 80.89 & 38.85 & 0.480 & 0.541 & -0.307 \\
Exponential & 113.0 & 59.09 & 0.523 & 0.155 & -0.124 \\
\hline & 83.15 & 83.15 & 1.0 & 2.0 & 6.0 \\
\hline Gamma & & Summer & & & \\
Weibull & 38.41 & 31.95 & 0.832 & 1.663 & 4.149 \\
Pearson 6 & 41.09 & 30.23 & 0.736 & 1.969 & 1.969 \\
Rayleigh & 41.12 & 31.61 & 0.768 & 1.537 & 3.544 \\
Beta & 38.41 & 20.08 & 0.523 & 0.631 & 0.245 \\
Kumaraswamy & 29.97 & 47.40 & 1.58 & 1.9 & 2.879 \\
Exponential & 27.44 & 41.52 & 1.51 & 1.787 & 2.763 \\
\hline
\end{tabular}

Table 6. Goodness-of-fit test ranking with the studied Distributions

\begin{tabular}{lcccccc}
\hline \multirow{2}{*}{ Distribution } & \multicolumn{2}{c}{$\begin{array}{c}\text { Kolmogorov } \\
\text { Smirnov }\end{array}$} & \multicolumn{2}{c}{$\begin{array}{c}\text { Anderson } \\
\text { Darling }\end{array}$} & \multicolumn{2}{c}{ Chi-Squared } \\
\cline { 2 - 7 } & Autumn & Summer & Autumn & Summer & Autumn & Summer \\
\hline Gamma & 1 & 1 & 1 & 1 & 2 & 4 \\
Weibull & 2 & 2 & 2 & 2 & 5 & 1 \\
Pearson 6 & 3 & 3 & 4 & 3 & 3 & 2 \\
Rayleigh & 4 & 4 & 3 & 5 & 1 & 3 \\
Beta & 5 & 7 & 5 & 7 & 4 & N/A \\
Kumaraswamy & 6 & 6 & 7 & 6 & 6 & N/A \\
Exponential & 7 & 5 & 6 & 4 & 7 & 5 \\
\hline
\end{tabular}

Note: Ranking is in the order of 1,2,3,4,5,6,7. 1 is the best ranking and 7 the worst ranking; NA: implies not applicable (By using EasyFit 5.1 Software program

Table 7. Quantile Estimates for Various Return Periods by EasyFit Program

\begin{tabular}{|c|c|c|c|c|c|c|c|c|c|c|c|}
\hline Probability, $\%$ & 1 & 3 & 5 & 10 & 25 & 50 & 75 & 90 & 95 & 97 & 99 \\
\hline Character & \multicolumn{3}{|c|}{ Very wet } & \multicolumn{2}{|c|}{ Wet } & Medium & \multicolumn{2}{|c|}{ Dry } & \multicolumn{3}{|c|}{ Very dry } \\
\hline Return Period, Year & 100 & 33 & 20 & 10 & 4 & 2 & 4 & 10 & 20 & 33 & 100 \\
\hline \multicolumn{12}{|l|}{ Autumn } \\
\hline Gamma & 197 & 168 & 154 & 134 & 105 & 77 & 55 & 39 & 32 & 27 & 20 \\
\hline Weibull & 164 & 147 & 139 & 126 & 103 & 79 & 57 & 39 & 29 & 24 & 16 \\
\hline Pearson 6 & 262 & 216 & 194 & 164 & 119 & 80 & 51 & 32 & 23 & 19 & 12 \\
\hline Rayleigh & 201 & 176 & 162 & 142 & 110 & 78 & 50 & 30 & 21 & 16 & 9 \\
\hline Beta & 180 & 163 & 153 & 136 & 107 & 76 & 50 & 33 & 26 & 23 & 18 \\
\hline Kumaraswamy & 224 & 217 & 211 & 198 & 162 & 110 & 62 & 34 & 25 & 22 & 18 \\
\hline Exponential & 383 & 292 & 249 & 191 & 115 & 58 & 24 & 9 & 4 & 3 & 1 \\
\hline \multicolumn{12}{|l|}{ summer } \\
\hline Gamma & 148 & 116 & 101 & 81 & 53 & 30 & 15 & 7 & 4 & 3 & 1 \\
\hline Weibull & 136 & 112 & 100 & 82 & 57 & 34 & 18 & 9 & 5 & 4 & 2 \\
\hline Pearson 6 & 147 & 117 & 103 & 83 & 56 & 33 & 18 & 9 & 6 & 4 & 2 \\
\hline Rayleigh & 93 & 81 & 75 & 66 & 51 & 36 & 23 & 14 & 10 & 8 & 4 \\
\hline Beta & 194 & 166 & 144 & 104 & 40 & 5 & 0.2 & 0.002 & 0 & 0 & 0 \\
\hline Kumaraswamy & 166 & 145 & 127 & 94 & 38 & 6 & 0.3 & 0.007 & 0 & 0 & 0 \\
\hline Exponential & 177 & 135 & 115 & 88 & 53 & 27 & 11 & 4 & 2 & 1 & 0.4 \\
\hline
\end{tabular}


Table 8. Quantile estimates for various return periods, (million $\mathrm{m}^{3}$ ) by CumFreq Program

\begin{tabular}{cccc}
\hline Year & Cumulative Frequency & Autumn & Summer \\
\hline 5 & 0.800 & 110 & 60 \\
10 & 0.900 & 139 & 74 \\
25 & 0.960 & 183 & 89 \\
50 & 0.980 & 222 & 102 \\
100 & 0.990 & 266 & 113 \\
200 & 0.995 & 317 & 124 \\
500 & 0.998 & 396 & 136 \\
\hline
\end{tabular}

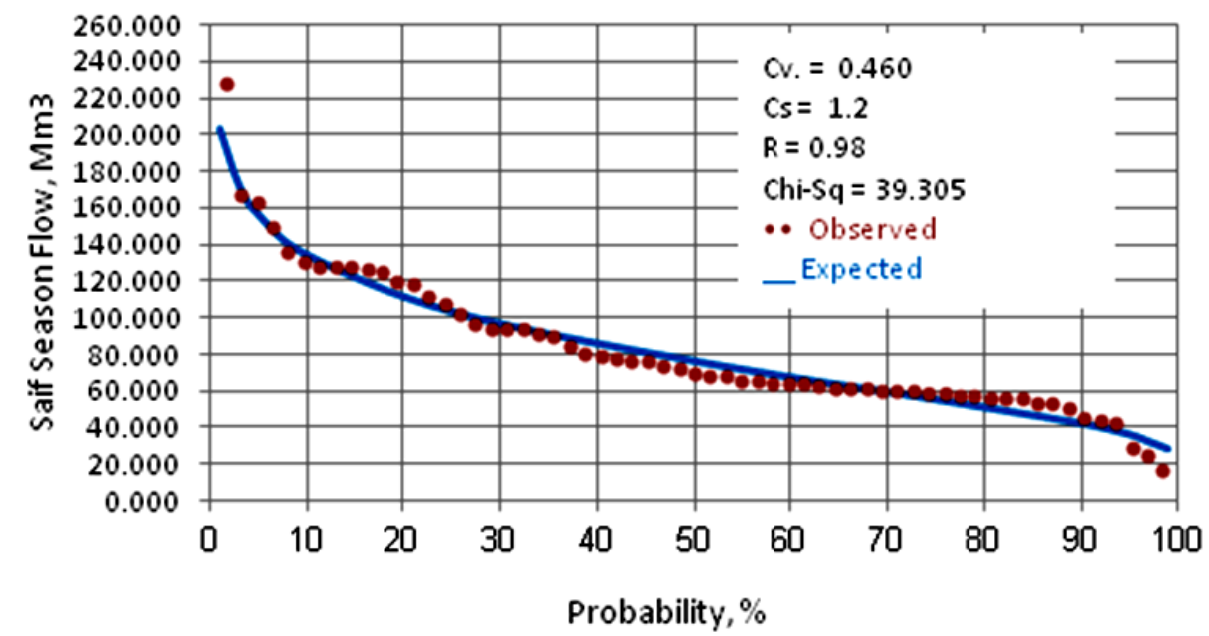

Figure 1. Flow probability Curve for the Autumn Season of Wadi Bana (1948-2008)

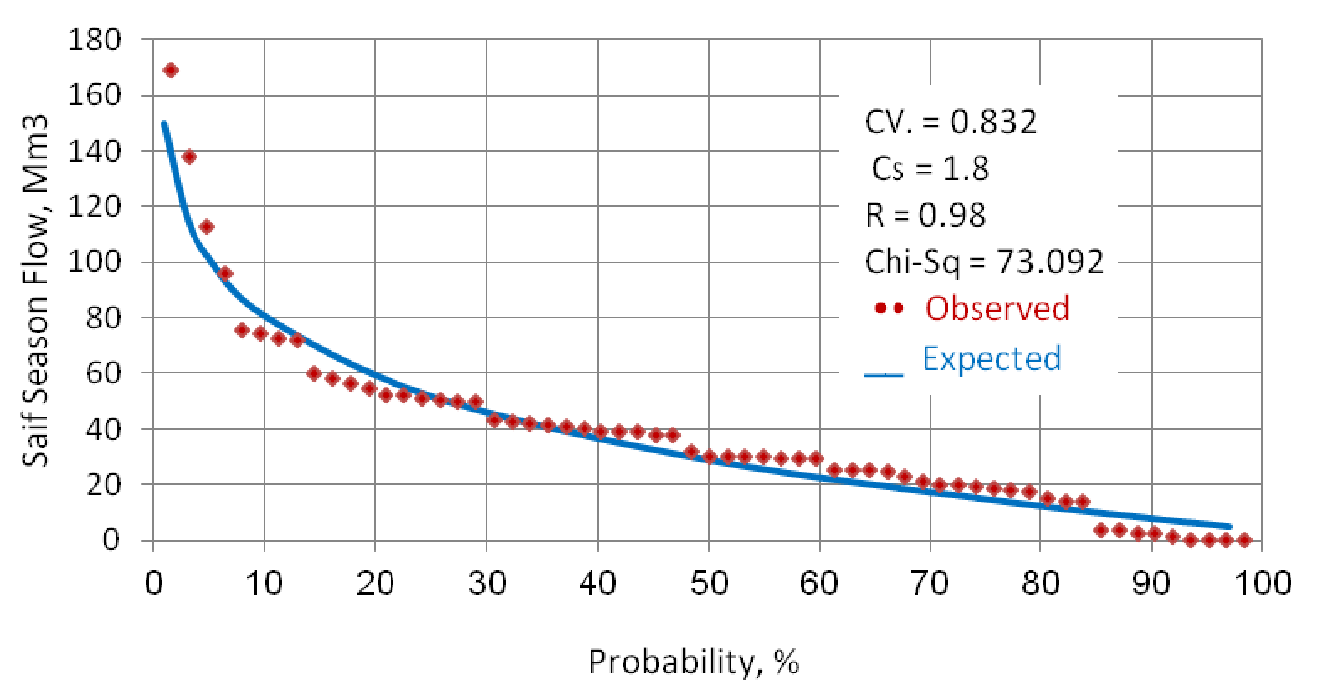

Figure 2. Flow probability Curve for the Summer Season of Wadi Bana $(1948-2008)$ 


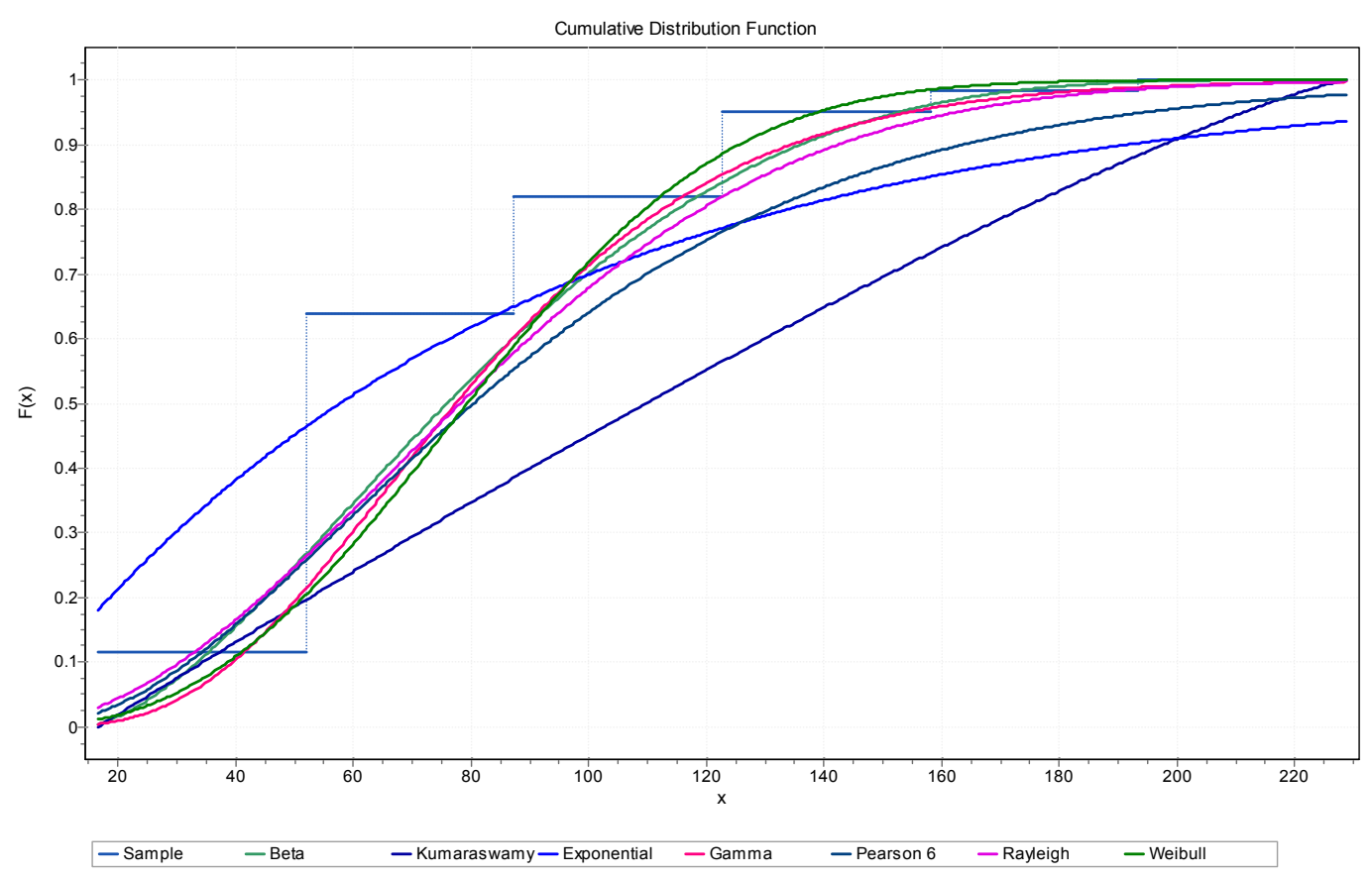

Figure 3. Cumulative Distribution Function for Autumn

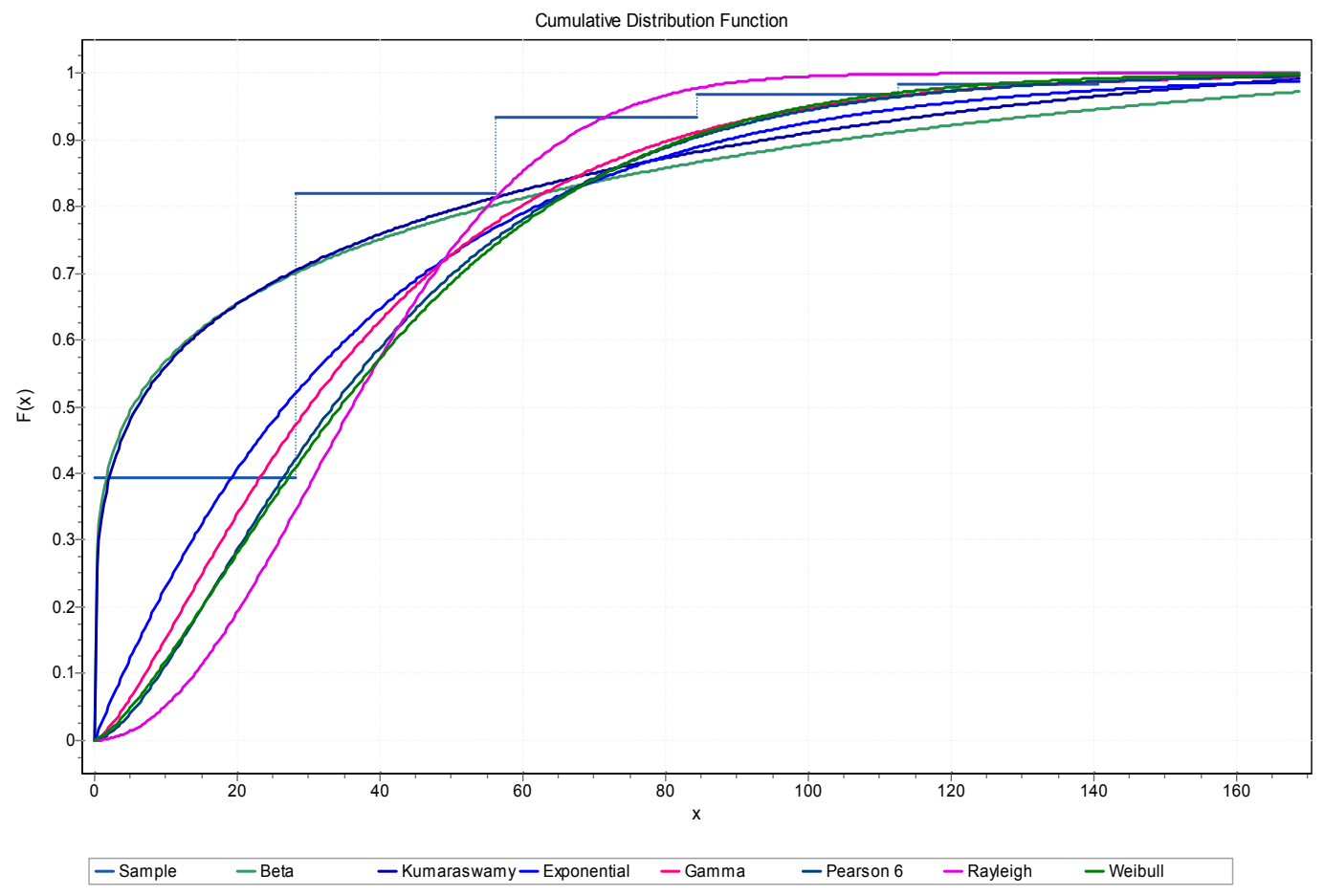

Figure 4. Cumulative Distribution Function for Summer 